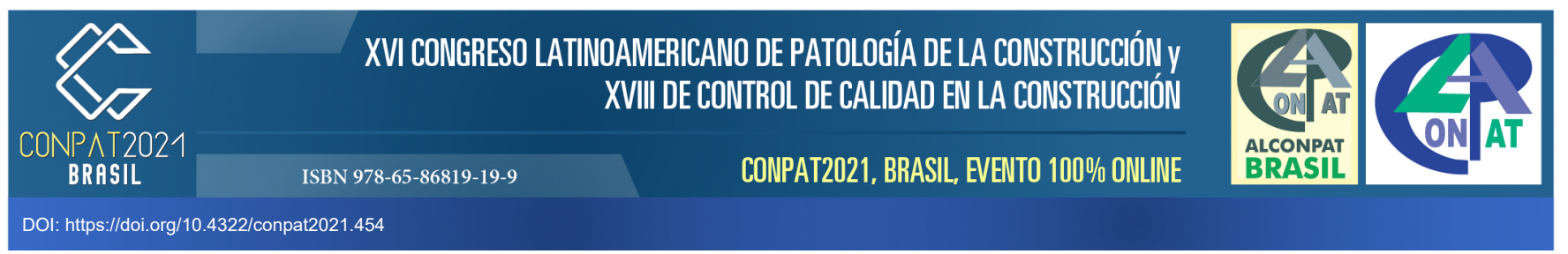

\title{
Análise das manifestações patológicas em uma edificação residencial de Francisco Beltrão - PR
}

\author{
T. V. de Toledo ${ }^{1}$, C. R. Eberle ${ }^{1}$, B. P. Dala Costa ${ }^{1}$, A. Frare ${ }^{1^{*}}$ \\ *Autor de Contato: frareandreza@gmail.com \\ ${ }^{1}$ Departamento de Engenharia Civil, Centro Universitário Campo Real, Guarapuava, Brasil
}

\begin{abstract}
RESUMO
As manifestações patológicas vêm sendo cada vez mais recorrentes na construção civil. Por isso, este trabalho tem como principal objetivo estudar e catalogar os tipos de ocorrências existentes em uma residência familiar, no município de Francisco Beltrão, bem como origem e soluções. Com essa pesquisa, concluímos que é de suma importância um engenheiro civil acompanhando a execução de uma obra, haja visto que a maioria dos problemas encontrados foram definidos como sendo má execução, a necessidade da utilização de materiais corretos e de qualidade para os processos construtivos e a manutenção preventiva para que não ocorram imprevistos.
\end{abstract}

Palavras-chave: Manifestação patológica. Problemas na execução. Construção Civil. 


\begin{abstract}
Pathological manifestations are becoming more and more recurrent in civil construction. Therefore, this work has as main objective to study and catalog the types of occurrences existing in a family residence, in the municipality of Francisco Beltrão, as well as origin and solutions. With this research, we conclude that it is of paramount importance for a civil engineer to monitor the execution of a work, given that most of the problems encountered were defined as poor execution, the need to use correct and quality materials for the construction and construction processes. preventive maintenance so that no unforeseen events occur.
\end{abstract}

Key words: Pathological manifestation. Problems in execution. Construction.

\title{
RESUMEN
}

Las manifestaciones patológicas han sido cada vez más recurrentes en la construcción civil. Por tanto, este trabajo tiene como objetivo principal estudiar y catalogar los tipos de sucesos existentes en una residencia familiar, en el municipio de Francisco Beltrão, así como su origen y soluciones. Con esta investigación, concluimos que es de suma importancia para un ingeniero civil monitorear la ejecución de una obra, dado que la mayoría de los problemas encontrados se definieron como mala ejecución, la necesidad de utilizar materiales correctos y de calidad para la construcción y construcción. procesos de mantenimiento preventivo para que no se produzcan imprevistos.

Palabras clave: Manifestación patológica. Problemas de ejecución. Construcción civil. 


\section{INTRODUÇÃO}

Desde os primórdios da civilização que o homem tem se preocupado com a construção de estruturas adaptadas às suas necessidades, sejam elas habitacionais, laborais, ou de infraestrutura. Com isto, a humanidade acumulou um grande acervo científico ao longo dos séculos, o que permitiu o desenvolvimento da tecnologia da construção, abrangendo a concepção, o cálculo, a análise e o detalhamento das estruturas, a tecnologia de materiais e as respectivas técnicas construtivas. (RIPPER; SOUZA, 1998).

Em decorrência às atualizações de técnicas, avanço de tecnologias e materiais, os processos construtivos se tornaram mais complexos, exigindo mão de obra qualificada e até mesmo especializações para quem fosse executar, o que dificultou muito, visto que nem sempre essas condições são aplicadas, acarretando assim, o desenvolvimento de manifestações patológicas com muito mais facilidade.

O objetivo principal deste trabalho é estudar as origens e formas de todas as manifestações patológicas encontradas em uma residência familiar no município de Francisco Beltrão, diagnosticando, apontando possíveis causas e possíveis soluções.

Com o grande catálogo das ocorrências patológicas, foi necessário fazer o estudo e análise de cada uma, visando solucionar os problemas. O estudo das manifestações patológicas permite um conhecimento mais aprofundado das causas, subsidia os trabalhos de recuperação e manutenção, e contribui para um maior entendimento de cada uma das etapas dos processos de produção das edificações, possibilitando a adoção de medidas preventivas (IOSHIMOTO, 1988).

\section{PROCEDIMIENTO}

\subsection{Local da pesquisa}

A pesquisa foi realizada em uma residência no município de Francisco Beltrão, que se localiza no sudoeste do estado do Paraná. O município foi fundado em 14 de dezembro de 1952, tendo atualmente, 67 anos, possui uma área territorial de $731,939 \mathrm{~km}^{2}$ e altitude de 570 metros. Possui 5 distritos administrativos (Francisco Beltrão, Jacutinga, Nova Concórdia, São Pio X e Secção Jacaré) e a população estimada em 92.216 pessoas. (IPARDES, 2020).

A residência se localiza em um bairro residencial, em uma via de acesso secundário ao município. Trata-se de um sobrado com aproximadamente $130 \mathrm{~m}^{2}$, compondo de uma suíte com closet, 2 quartos, banheiro social, sala de jantar, cozinha, lavabo, garagem para dois carros, lavanderia e churrasqueira, tem recuo frontal e sobra de terreno atrás. A edificação foi construída por uma incorporadora da região em 2015, e atualmente o imóvel encontra-se alugado. A Figura 1 mostra o croqui da residência. 

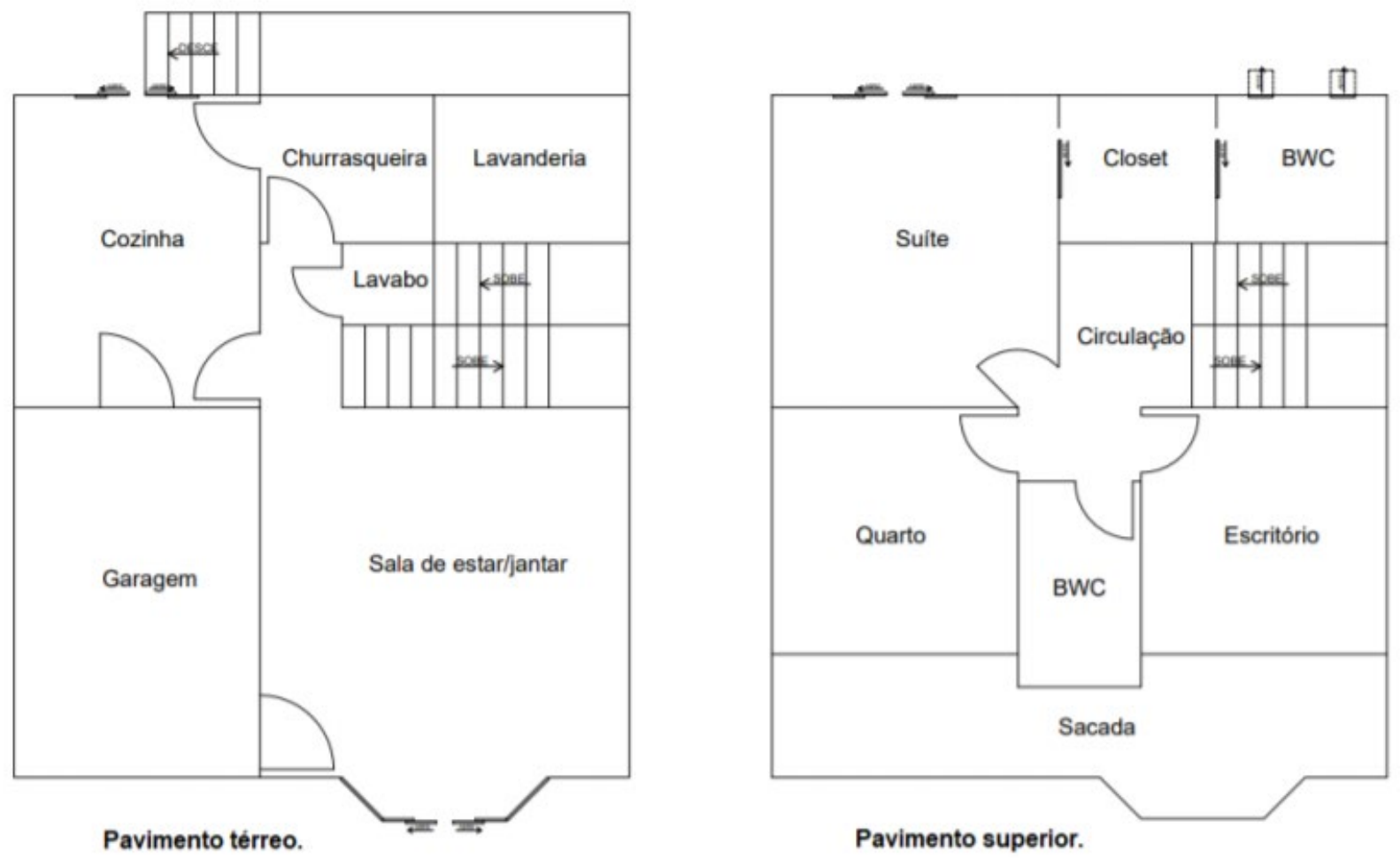

Figura 1. Croqui da resisdência

A pesquisa realizada se desenvolveu através do estudo de caso que aconteceu por meio de uma vistoria técnica, com visita à residência no dia 30 de setembro de 2020, a qual teve duração de aproximadamente 2 horas e contou com a ajuda da moradora para a apresentação da residência e dos cômodos de localização dos problemas, para a identificação das manifestações patológicas que foram examinadas de acordo com registros fotográficos feitos durante a vistoria.

\section{RESULTADOS E DISCUSSÕES}

\subsection{Fissuras}

Nas Figuras 2(a) e 2(b), notam-se fissuras na diagonal e horizontal, nos cantos da esquadria. Já as figuras 2(c) e 2(d) mostram fissuras horizontais em paredes de alvenaria, provavelmente provenientes da estrutura. 

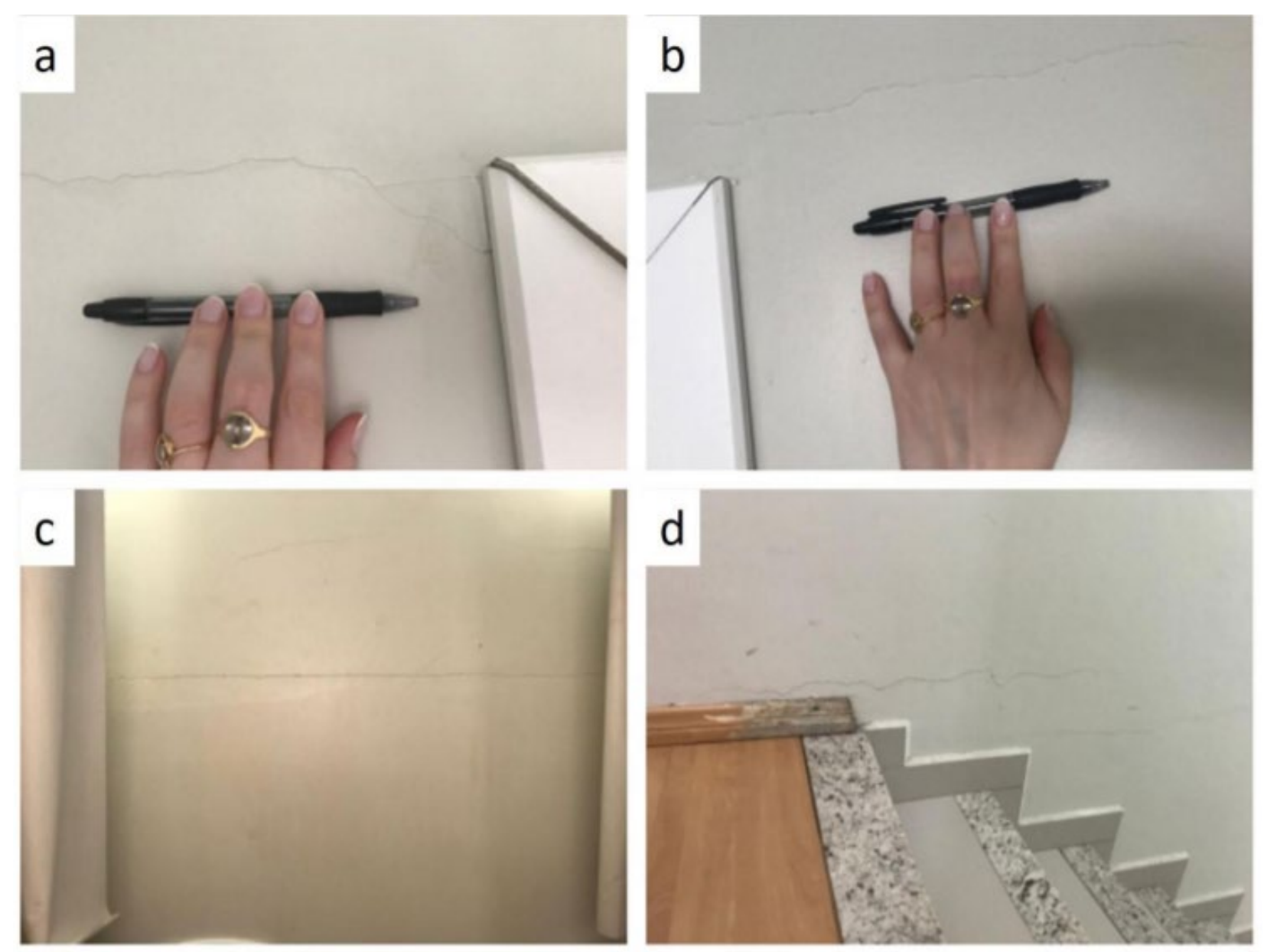

Figura 2. Fissuras

As fissuras por sobrecarga em torno de aberturas ocorrem em paredes de alvenaria descontínuas, com uma ou mais aberturas, submetidos a carregamentos de compressão e têm como característica a formação de fissuras a partir dos vértices das aberturas (THOMAZ, 1989).

Os principais mecanismos de formação das fissuras, para que se possa ter uma compreensão adequada para orientar decisões eficazes à recuperação de componentes trincados ou à adoção de medidas preventivas, são:

- Movimentações provocadas por variações térmicas e de umidade;

- Atuação de sobrecargas ou concentração de tensões;

- Deformabilidade excessiva das estruturas;

- Recalques diferenciados das fundações;

- Retração de produtos à base de ligantes hidráulicos;

- Alterações químicas de materiais de construção (LIMA, 2015).

As fissuras apresentadas nas Figuras 2(a) e 2(b) podem apresentar-se com diversas configurações, em função de diversos fatores como dimensões da parede e das aberturas, materiais constituintes das paredes, dimensão e rigidez de vergas e contravergas, deformação e comportamento da alvenaria e de seu suporte (THOMAZ, 1989).

As fissuras apresentadas nas Figuras 2(c) e 2(d), ainda segundo Thomaz (1989), podem ocorrer por esmagamento de argamassa, de assentamento pelas sobrecargas uniformemente distribuídas. Ocorrem também, principalmente, por fundações mal calculadas, tipo de fundação para o solo incorretas, cálculo estrutural errado e dimensionamento incorreto da ferragem. Para corrigir, a decisão do material escolhido para preenchimento da fissura passa pela avaliação da mesma. Assim, quando a fissura estiver ativa (houver movimento), procede-se apenas com a vedação das 
fissuras ou com o eventual preenchimento dos vãos com material elástico e não resistente, permitindo sua movimentação e protegendo o concreto. Para fissuras passivas, que não se movimentam, recomenda-se material rígido. Este material não terá somente a função de proteção contra agentes externos, mas como também de reestabelecer o monolitismo da peça estrutural (OLIVEIRA, 2015).

\subsection{Fissuras na laje}

A Figura 3 apresenta fissuras na laje da cozinha.

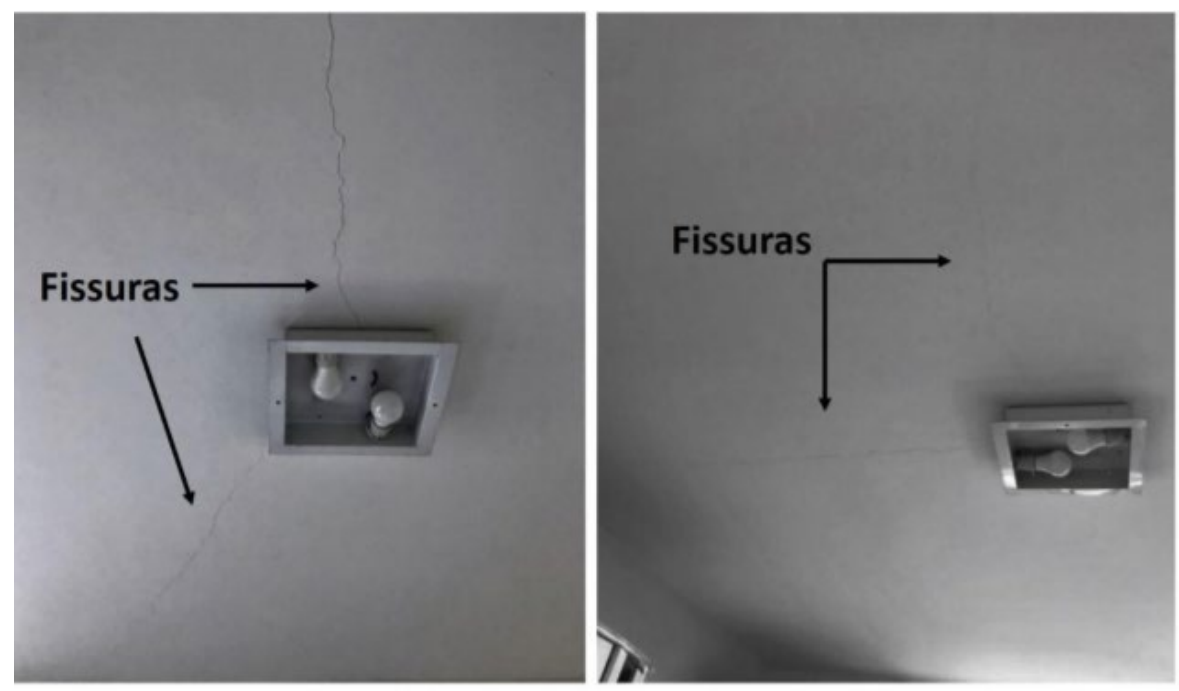

Figura 3. Fissuras na laje

As fissuras em questão aparecem nos dois eixos e se encontram em um determinado ponto. Podem ser por várias causas, principalmente por execução: um possível rompimento de armadura positiva, com o furo feito para instalação elétrica (luminária) provocando o acúmulo de tensão nesse ponto, ou a falta da armadura. Segundo Farias (2019), furos e aberturas são normalmente realizados pela falta de compatibilização de projetos, realizados durante a fase de execução, sem respeitar as especificações da norma. A correção se dá pelo mesmo método descrito anteriormente.

\subsection{Infiltração, bolor e mofo}

Causado por umidade, o mofo/bolor pode ser prejudicial para a saúde e para o imóvel. A Figura 4 mostra focos desta manifestação patológica na residência. 

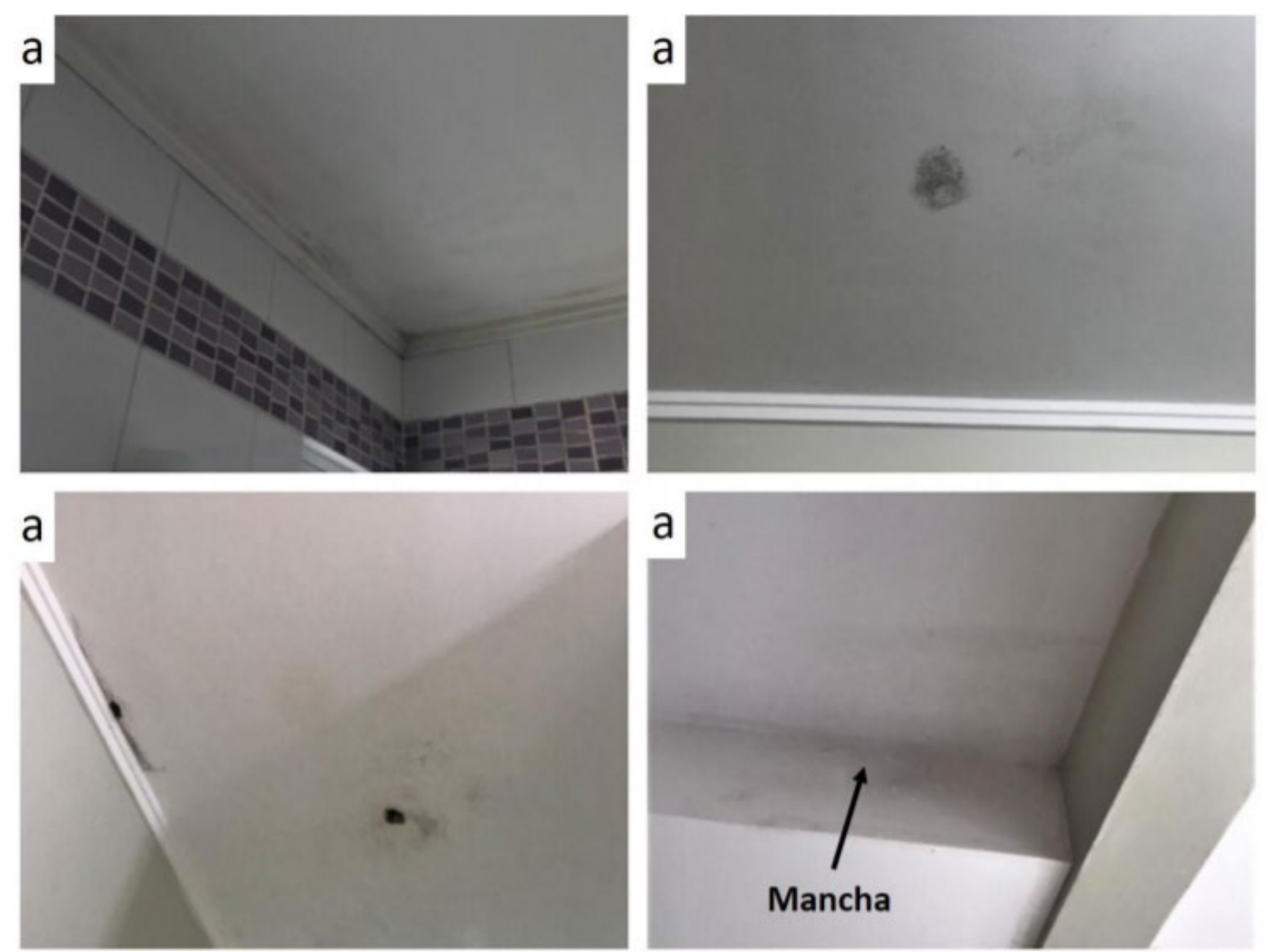

Figura 4. Bolor em forro do banheiro

Na Figura 4 são perceptíveis manchas de mofo ou bolor. A Figura 4(a) teve a manifestação patológica causada por condensação da água, com o vapor de um banheiro.

Na Figura 4(b), a mancha pode ser causada por infiltração de água através de encanamento.

A Figura 4(c) apresenta perfurações no gesso provenientes da umidade de goteira, possivelmente por telha quebrada e ausência ou má impermeabilização, erros de execução e de projeto.

A Figura 4(d) corresponde a infiltração proveniente de outra manifestação patológica que ocorre no banheiro no pavimento superior da residência, o qual tem um desnível e a água fica acumulada, descolando os rejuntes e passando a água para a laje.

A água que não é absorvida fica alojada nos materiais ou ambientes, formando um local propício para a proliferação de microrganismos. Para as manifestações patológicas já instaladas, a primeira ação a ser feita é a identificação da infiltração e o seu estancamento. Limpeza das superfícies afetadas com produtos fungicidas, podendo ser feita até a troca do material existente ou pintura nova.

Como prevenção, Alucci, Flauzino e Milano (1985) dizem que mofo e bolor podem ser evitados na fase de projeto já, garantindo ventilação, iluminação e sol para os ambientes, idealizar a diminuição de risco de condensação nas superfícies internas e riscos de infiltrações. Impermeabilizações e a utilização de produtos que contenham impermeabilizantes, também são fundamentais.

\subsection{Empolamento e descascamento de pintura}

A Figura 5 apresenta as manifestações patológicas na pintura. 


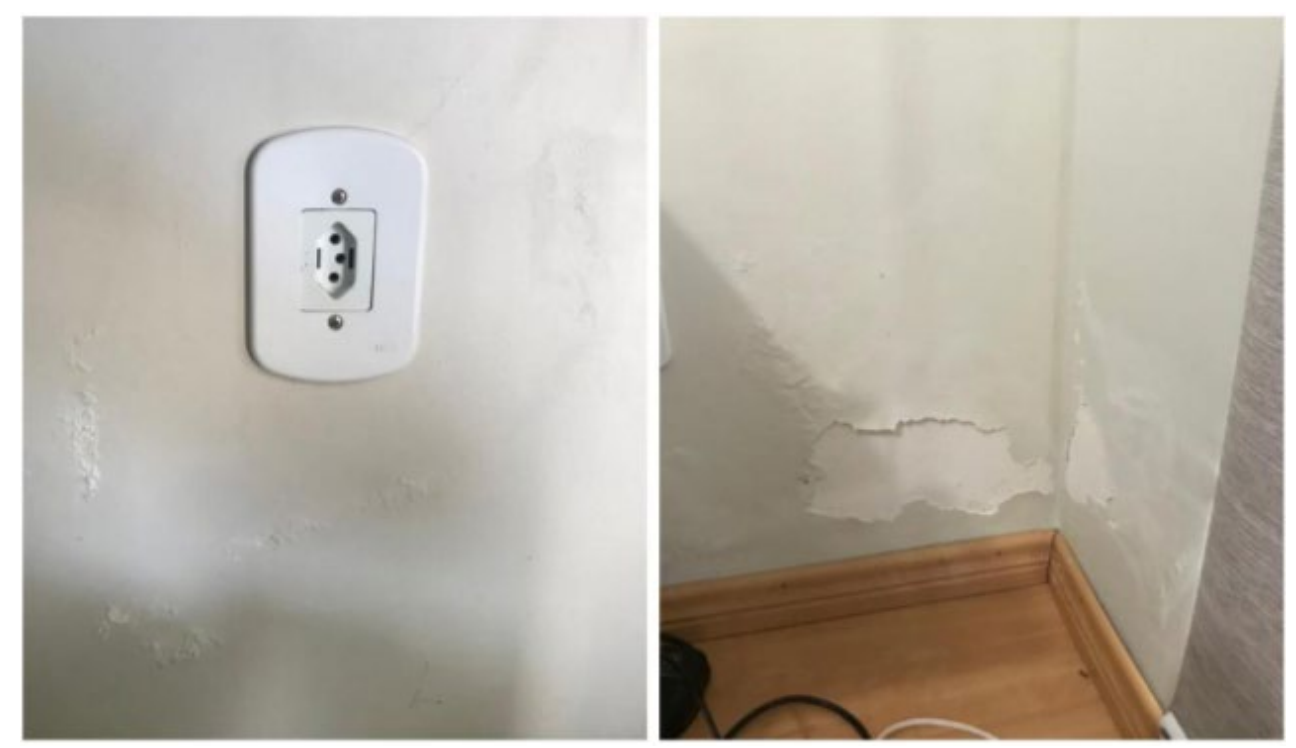

Figura 5. Manifestações patológicas na pintura

Na Figura 5, é possível visualizar o empolamento e descascamento da pintura, no meio da parede e próximo ao rodapé. Segundo a prefeitura municipal de Belo Horizonte (2019), as bolhas são causadas por falta de aderência do produto aplicado devido à presença de pó (tinta antiga pulverulenta) sobre a superfície. O descascamento ocorre pelos mesmos motivos das bolhas, adicionando a possível pintura sobre caiação ou quando, na primeira pintura sobre reboco, a primeira demão não foi bem diluída.

A correção dos locais com bolhas deve ser realizada da seguinte forma: a remoção de todas as bolhas, partes soltas e mal aderidas com uso de espátula, escova de aço e lixa, aplicar na superfície uma demão de fundo preparador para paredes a base de água. Esse produto penetra na superfície e agrega as partículas tornando-as coesas para a sequência da pintura. Nivelar a superfície com massa corrida (áreas internas e secas) e repintar a superfície com o produto desejado. A correção do descascamento recomenda-se raspar ou escovar a superfície até a remoção total das partes soltas ou mal aderidas. Em seguida deve-se aplicar uma demão de fundo preparador de paredes base d'água e aplicar o acabamento (BELO HORIZONTE, 2019).

Porém seria necessária uma avaliação mais afundo para a verificação da causa da patologia, pois a mesma pode ocorrer devido a presença de umidade, por infiltrações, causadas por falhas nas impermeabilizações, trincas e vazamentos em tubulações, não sendo possível corrigir apenas com reparos na pintura.

\subsection{Descolamento do revestimento}

A Figura 6 apresenta o descolamento de revestimento cerâmico. 


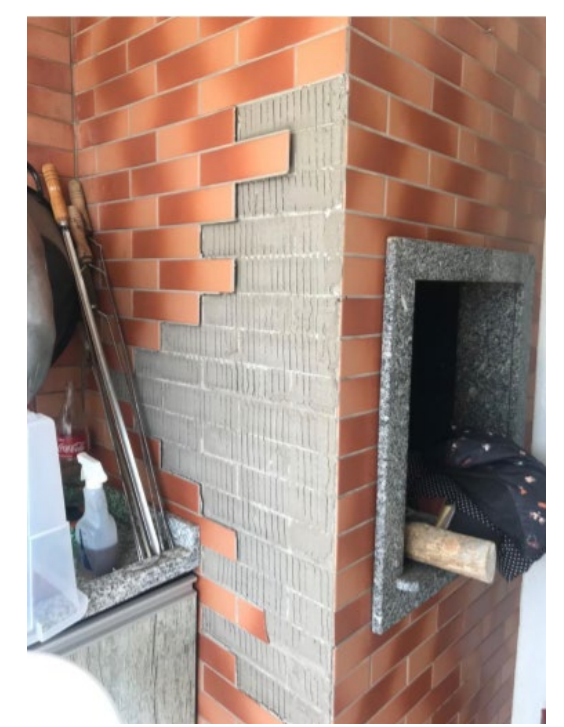

Figura 6. Descolamento de revestimento

Na Figura 6, houve o descolamento do revestimento cerâmico na churrasqueira. Esta foi construída com tijolos refratários, que é o material adequado para suportar altas temperaturas. Entretanto, sua execução não foi realizada com argamassa e rejunte refratários, ou até mesmo o revestimento não era o indicado à altas temperaturas, desta forma, o calor foi conduzido pela massa de assentamento e atingiu o revestimento externo da churrasqueira. Essas condutas somadas à má execução com o preenchimento incompleto do verso das placas ou o tempo em aberto da argamassa colante excedido, ocasionou o descolamento das placas do revestimento.

Segundo Deutsch (2011), a base que receberá os revestimentos deverá ser corretamente especificada e preparada, para se evitarem problemas de falta de aderência, entre outros. As argamassas, assim como o concreto, também são plásticas nas primeiras horas, e endurecem com o tempo, ganhando elevada resistência e durabilidade. A correta especificação da dosagem é essencial para um bom desempenho e trabalhabilidade. Para se obter uma boa trabalhabilidade é importante a adição de aditivos plastificantes e incorporadores de ar.

\section{Considerações finais}

O estudo de caso possibilitou a avaliação das manifestações patológicas da residência, através de vistoria no local com registro fotográfico, bem como suas causas e possíveis soluções. Permitiu descobrir que a maioria das ocorrências são provenientes de má execução ou de falhas no projeto, mão de obra desqualificada ou materiais inadequados.

A importância das manifestações patológicas deve-se ao fato de que contribui para a redução de vida útil da edificação, qualidade, durabilidade e desempenho, comprometendo a estrutura e, portanto, suas funções. Se tratando de manutenção, a preventiva sempre será a melhor opção, haja vista que não existem manifestações patológicas a serem tratadas e sim prevenidas, diminuindo assim, o custo de possíveis reparos e soluções, até mesmo estruturais, que uma manutenção corretiva teria.

Os objetivos deste trabalho foram concluídos, podendo ser apontadas as causas de cada ocorrência e possíveis soluções para todas as manifestações patológicas encontradas e catalogadas, com suas devidas características e indicando materiais adequados, acompanhados de mão de obra qualificada.

Para projetos futuros, indica-se sempre um engenheiro civil acompanhando a execução da obra, com um projeto e mão de obra qualificados. Incluir projetos de gestão com ferramentas de 
qualidade também são ótimas estratégias para que se evite a ocorrência das manifestações patológicas, aumentando assim, a vida útil da edificação e a sua qualidade, garantindo às pessoas moradoras um bom uso da sua residência.

\section{REFERENCIAS}

ABNT - ASSOCIAÇÃO BRASILEIRA DE NORMAS TÉCNICAS. NBR 15575-1: Edificações habitacionais - Desempenho, Parte 1: Requisitos gerais. Rio de Janeiro, 2013.

ALMEIDA, Maria Lúcia Pacheco de. Como elaborar monografias. 4. ed. rev. e atual. Belém: Cejup, 1996. cap. 4, p. 101-110.

ALUCCI, M. P., FLAUZINO, W. D., MILANO, S. Bolor em Edifícios: Causas e Recomendações. Tecnologia de Edificações, São Paulo. Pini, IPT - Instituto de Pesquisas Tecnológicas do Estado de São Paulo, Coletânea de trabalhos da Div. De Edificações do IPT. 1988.

ANDRADE, T.; SILVA, A. J. C. Patologia das Estruturas. In: ISAIA, Geraldo Cechella (Ed.). Concreto: ensino, pesquisa e realizações. São Paulo: IBRACON, 2005.

BELO HORIZONTE, Prefeitura Municipal de. Superintendência de Desenvolvimento da Capital. Diretoria de Projetos. Caderno de encargos. Belo Horizonte, 2020. Disponível em: https://prefeitura.pbh.gov.br/sites/default/files/estrutura-degoverno/obras-e-

infraestrutura/2019/Capitulo_17_R8.pdf. Acesso em: 25 nov. 2020.

BERTI, João Vitor Meneguetti; SILVA JÚNIOR, Gean Pereira da; AKASAKI, Jorge Luís. Estudo da origem, sintomas e incidências de manifestações patológicas do concreto. Revista Científica ANAP Brasil, [S.1.], v. 12, n. 26, dez. 2019. ISSN 1984- 3240. Disponível em: $<$ http://www.amigosdanatureza.org.br/publicacoes/index.php/anap_brasil/article/view/2228>.

Acesso em: 16 Out. 2020.

CERVO, Amado Luiz; BERVIAN, Pedro Alcino. Metodologia Científica. São Paulo: Mc GrawHill do Brasil, 1976. 69 p.

CORRÊA, Ederson Souza. Patologias Decorrentes de Alvenaria Estrutural. 2010. 47 f. TCC (Graduação) - Curso de Engenharia Civil, Universidade da Amazônia, Belém, 2010.

CREMONINI, Ruy Alberto. Incidência de manifestações patológicas em unidades escolares na região de Porto Alegre: recomendações para projeto, execução e manutenção. 1988. $169 \mathrm{f}$. Dissertação (Mestrado) - Curso de Engenharia Civil, Universidade Federal do Rio Grande do Sul, Porto Alegre, 1988.

DEUTSCH, Simone Feigelson. Perícias de Engenharia: a Apuração dos Fatos. São Paulo: Leud, 2011.

DEUTSCH, Simone Feigelson. Periciais de Engenharia a Apuração dos Fatos. São Paulo, Leud 2013. 
FARIAS, Ianna Karoline Martins Guimarães. Influência de Furos e Aberturas em Estruturas de concreto Armado - Análise de Furos Horizontais para Passagem de Tubulações em Vigas Convencionais. 2019. 66 f. TCC (Graduação) - Curso de Engenharia Civil, Universidade Federal do Maranhão, São Luis - Ma, 2019.

HELENE, P. Corrosão em Armaduras para Concreto Armado. Editora Pini, São Paulo, 1986.

HELENE, Paulo. Manutenção para Reparo, Reforço e Proteção de Estruturas de Concreto. Pini, $2^{\mathrm{a}}$ ed. São Paulo, 1992.

HELENE, Paulo. Manual de Reparo, Proteção e Reforço de Estruturas de Concreto. Editora Rehabilitar, São Paulo, 2003.

IOSHIMOTO, Eduardo. Incidência de Manifestações Patológicas em Edificações Habitacionais. Tecnologia de Edificações, São Paulo. Pini, IPT - Instituto de Pesquisas Tecnológicas do Estado de São Paulo, Coletânea de trabalhos da Div. De Edificações do IPT. 1988. p. 545-48.

LAKATOS, Eva Marina; MARCONI, Marina de Andrade. Metodologia do Trabalho Científico. 2. ed. São Paulo: Atlas, 1987. 66 p

LIMA, Bruno Santos de. Principais Manifestações Patológicas em Edificações Residenciais Multifamiliares. 2015. 66 f. TCC (Graduação) - Curso de Engenharia Civil, Universidade Federal de Santa Maria, Santa Maria Rs, 2015.

LICHTENSTEIN, Norberto Blumenfeld. Patologia das Construções. São Paulo: Departamento de Engenharia de Construção Civil da Escola Politécnica da Usp, 1986.

MACHADO, Ari de Paula. Reforço de Estruturas de Concreto Armado com Fibras de Carbono. São Paulo: Pini, 2002.

NETO, Francisco Maia. Patologia das Construções. Artigos do Jornal Estado de Minas, 16 out. 2011. Disponível em: http://www.precisao.eng.br/fmnresp/patologia.html\#gsc.tab=0. Acesso em: 15 out. 2020.

OLIVEIRA, Julio Cesar Costa de. Técnicas Para Intervenção Em Estruturas De Concreto Armado. 2015. 61 f. TCC (Graduação) - Curso de Engenharia Civil, Escola Politécnica da Universidade Federal do Rio de Janeiro, Rio de Janeiro, 2015.

PINA, Gregório Lobo de. Patologia nas Habitações Populares. 2013. 102 f. Monografia (Especialização) - Curso de Engenharia Civil, Universidade Federal do Rio de Janeiro, Rio de Janeiro, 2013.

ROÇA, G. B. Análise das Manifestações Patológicas de Uma Edificação Residencial Estudo de Caso. Universidade Tecnológica Federal do Paraná. Curitiba, 2014.

SANTOS, Tatiana dos. Análise das Patologias no Colégio Estadual Reinaldo SASS no Município de Francisco Beltrão - PR. 2018. 134 f. TCC (Graduação) - Curso de Engenharia Civil, União de Ensino do Sudoeste do Paraná - Faculdade Educacional de Francisco Beltrão, Francisco Beltrão, 2018. 
SILVA, Luiza Kilvia da. Levantamento de Manifestações Patológicas em Estruturas de Concreto Armado no Estado do Ceará. 2011. 61 f. Monografia (Especialização) - Curso de Engenharia Civil, Universidade Federal do Ceará, Fortaleza, 2011.

SOTANA, Adriana Felipe et al. Patologia das Estruturas e Pisos de Concreto Armado e Revestimento. 2012. 33f. Trabalho apresentado à disciplina de Construção Civil II, Chapecó/SC, 2012.

SOUZA, Vicente Custódio Moreira de; RIPPER Thomaz. Patologia, Recuperação e Reforço de Estruturas de Concreto. São Paulo: Pini, 1998. 262 p.

THOMAZ, Ercio. Trincas em edifício: Causas, Prevenção e Recuperação. $1^{\mathrm{a}}$ ed. São Paulo, Pini, 1989. 